\title{
Article
}

\section{Is testosterone linked to human aggression? A meta-analytic examination of the relationship between baseline, dynamic, and manipulated testosterone on human aggression}

Geniole, SN, Bird, BM, McVittie, JS, Purcell, RB, Archer, John and Carre, JM

Available at http://clok.uclan.ac.uk/33858/

Geniole, SN, Bird, BM, McVittie, JS, Purcell, RB, Archer, John ORCID: 00000003-0483-1576 and Carre, JM (2020) Is testosterone linked to human aggression? A meta-analytic examination of the relationship between baseline, dynamic, and manipulated testosterone on human aggression. Hormones and Behavior, 123 (104644). ISSN 0018-506X

It is advisable to refer to the publisher's version if you intend to cite from the work. http://dx.doi.org/10.1016/j.yhbeh.2019.104644

For more information about UCLan's research in this area go to http://www.uclan.ac.uk/researchgroups/ and search for <name of research Group>.

For information about Research generally at UCLan please go to http://www.uclan.ac.uk/research/

All outputs in CLoK are protected by Intellectual Property Rights law, including Copyright law. Copyright, IPR and Moral Rights for the works on this site are retained by the individual authors and/or other copyright owners. Terms and conditions for use of this material are defined in the policies page. 
Is testosterone linked to human aggression? A meta-analytic examination of the relationship between baseline, dynamic, and manipulated testosterone on human aggression

Geniole, S.N., Bird, B.M., McVittie, J.S., Purcell, R.B., Archer, J., \& Carré, J.M* .

* Correspondence should be addressed to:

Justin M. Carré, Ph.D

Associate Professor

Department of Psychology

Nipissing University

100 College Dr.

North Bay, Ontario

P1B 8L7

Email: justinca@nipissingu.ca 


\begin{abstract}
Testosterone is often considered a critical regulator of aggressive behaviour. There is castration/replacement evidence that testosterone indeed drives aggression in some species, but causal evidence in humans is generally lacking and/or-for the few studies that have pharmacologically manipulated testosterone concentrations-inconsistent. More often researchers have examined differences in baseline testosterone concentrations between groups known to differ in aggressiveness (e.g., violent vs non-violent criminals) or within a given sample using a correlational approach. Nevertheless, testosterone is not static but instead fluctuates in response to cues of challenge in the environment, and these challenge-induced fluctuations may more strongly regulate situation-specific aggressive behaviour. Here, we quantitatively summarize literature from all three approaches (baseline, change, and manipulation), providing the most comprehensive metaanalysis of these testosterone-aggression associations/effects in humans to date. Baseline testosterone shared a weak but significant association with aggression $(r=0.054,95 \% \mathrm{CIs}[0.028$, $0.080])$, an effect that was stronger and significant in men $(r=.071,95 \%$ CIs $[.041, .101])$, but not women $(r=.002,95 \%$ CIs $[-.041, .044])$. Changes in T were positively correlated with aggression $(r=0.108,95 \%$ CIs $[0.041,0.174])$, an effect that was also stronger and significant in men $(r=$ $0.162,95 \%$ CIs [0.076, 0.246]), but not women ( $r=0.010,95 \%$ CIs [-0.090, 0.109]). The causal effects of testosterone on human aggression were weaker yet, and not statistically significant ( $r=$ 0.046, 95\% CIs -0.015, 0.108]). We discuss the multiple moderators identified here (e.g., offender status of samples, sex) and elsewhere that may explain these generally weak effects. We also offer suggestions regarding methodology and sample sizes to best capture these associations in future work.
\end{abstract}

Keywords: challenge hypothesis, androgens, sex differences, pharmacological challenge 
Aggression, especially in its more extreme forms — violence, homicide, and war — is one of the leading causes of death, with homicide alone predicted to claim more lives in 2030 than highly prevalent diseases such as Alzheimer's and Breast Cancer (World Health Organization, 2010). Aggression has been operationalized as an act intended to harm, either physically or non-physically (e.g., financially, psychologically), another individual who would rather avoid such treatment (Baron \& Richardson, 1994). Although there are multiple factors (e.g., context or personality traits) that contribute to the expression of aggression (e.g., see meta-analyses in Bettencourt \& Kernahan, 1997; Bettencourt \& Miller, 1996; Greitemeyer \& Sagioglou, 2016; Hershcovis et al., 2007; Jones, Miller, \& Lynam, 2011), one biological factor that has received much attention to date is the hormone testosterone. Berthold, in the mid $19^{\text {th }}$ century, discovered that removing both testes from developing male chickens (at 2 or 3 months of age) prevented their normal development of secondary sexual characteristics and — most relevant here-aggressive behaviour (Berthold \& Quiring, 1944). When he repeated the same procedure - but transplanted one testis taken from another chicken — the expected secondary sexual characteristics and male-typical aggressive behaviour developed normally. Given the importance of the testes for testosterone secretion, this and other non-human animal studies (e.g., mice, Beeman, 1947; macaques, Takeshita, Huffman, Kinoshita, \& Bercovitch, 2017) showing decreased aggression following castration/ablation, suggest that the hormone may modulate this type of behaviour in humans.

There are certainly strong lay beliefs about its aggression-potentiating effects (e.g., Eisenegger, Naef, Snozzi, Heinrichs, \& Fehr, 2010) and some circumstantial evidence seems consistent with the idea that the hormone may promote aggression: demographic groups tending to be more aggressive, particularly physically aggressive and/or homicidal (e.g., 15 - 29 year old males, Daly \& Wilson, 1988; M. Wilson \& Daly, 1985; World Health Organization, 2010) have higher concentrations of testosterone than do other demographic groups (e.g., women, older men, Handelsman, Sikaris, \& Ly, 2016). Nevertheless, early studies that more directly examined groups known to differ in violence (e.g., criminals incarcerated for violent versus non-violent criminals: 
Bain, Langevin, Dickey, \& Ben-Aron, 1987; Ehrenkranz, Bliss, \& Sheard, 1974) or correlations between testosterone and aggression within a given sample of participants (e.g., Kreuz \& Rose, 1972; Persky, Smith, \& Basu, 1971; Scaramella \& Brown, 1978), found mixed and/or weak support for this link. Synthesizing some of this earlier literature (pre-2005), a meta-analysis revealed a significant—but small $(r=.08)$-association between testosterone and various indices of human aggression (Archer, Graham-Kevan, \& Davies, 2005). Further, early studies employing an experimental approach by pharmacologically elevating concentrations of testosterone (e.g., through weekly injections) for a prolonged period yielded mixed support for testosterone's causal role in promoting human aggression (e.g., O’Connor, Archer, Hair, \& Wu, 2002; O’Connor, Archer, \& Wu, 2004; Pope, Kouri, \& Hudson, 2000; Yates, Perry, MacIndoe, Holman, \& Ellingrod, 1999).

One explanation for this relatively weak relationship is that many of these earlier studies used self-report rather than behavioural measures of aggression, which may produce lower associations given self-reported behaviour may be more prone to response biases and inconsistent responding (e.g., Strang, Peterson, Hill, \& Heiman, 2013), and not always map onto aggressive behaviour (reviewed in Baumeister, Vohs, \& Funder, 2007; Lobbestael, 2015). Further, these oftemployed questionnaires tend to assess more stable, or trait levels of aggression, but this behaviour is highly context- or situation- dependent. For example, aggression is expressed far more frequently when an individual is provoked, their goals are thwarted or challenged, or they experience some otherwise aversive event (e.g., for recent review, see Groves \& Anderson, 2018). Similarly, these studies often examined stable, trait, or baseline concentrations of testosterone, but the hormone's concentrations fluctuate over time and across situations. Models of the testosterone-aggression relationship in human and non-human animals emphasize this context-dependency. For example, the Fitness Model of Testosterone Dynamics - and the Challenge Hypothesis (Wingfield, Hegner, Dufty, \& Ball, 1990; applied to humans, Archer, 2006), upon which the fitness model is largely based-posit that testosterone responds to cues in the environment that signal a potential fitnessrelated challenge or opportunity (e.g., provocation, competition). These challenge-related surges in 
testosterone, in turn, drive behavioural responses, such as aggression, aimed at protecting or enhancing fitness. Indeed, studies capturing testosterone changes during competitive interactions have found the changes to correlate with, or positively predict, aggression measured either concurrently with, or after, the testosterone changes (e.g., Carré, Campbell, Lozoya, Goetz, \& Welker, 2013; Carré, Gilchrist, Morrissey, \& McCormick, 2010; Carré, Putnam, \& McCormick, 2009; Geniole, Carré, \& McCormick, 2011; Klinesmith, Kasser, \& McAndrew, 2006).

Nevertheless, these links are not straightforward, and sometimes depend on factors such as personality traits or social context (e.g., Carré et al., 2010; Norman, Moreau, Welker, \& Carré, 2014; Welker et al., 2017). Similarly, when single doses of testosterone have been administered to mimic these transient surges, their overall and/or direct effects on aggression have been relatively weak, moderated by other factors (e.g., personality, provocation, Carré et al., 2017; Geniole et al., 2019) or mediated by negative affect (Panagiotidis et al., 2017). Therefore, although fluctuations in testosterone appear to more strongly predict aggression than stable, baseline concentrations, they may nonetheless be limited in their predictive validity given their dependence on personality, situation, and affect.

Here, we synthesize this testosterone-aggression literature, providing a comprehensive and quantitative overview that updates the meta-analytic estimate of the association between baseline testosterone and aggression, including effects from both group comparison and correlational studies. We also provide, for the first time, a meta-analytic estimate of the association between changes in testosterone and aggression, with the hypothesis that such links will be stronger than those involving baseline concentrations (e.g., see studies in which changes in, but not baseline, testosterone predicted aggression, Carré et al., 2013, 2010, 2009; Geniole et al., 2011). And finally, we examine the effects of exogenous testosterone on aggression, identifying the overall causal effect of the hormone on aggression. 


\section{Methods}

\section{Coding and extracting effect and sample sizes}

We extracted effect sizes based on bivariate associations (e.g., Pearson's product-moment correlation, Spearman's rho) or means and standard deviations, allowing for an estimate of the zeroorder association between testosterone and aggression, or between group membership - aggressive vs non-aggressive (e.g., violent vs non-violent prisoners) - and testosterone (see Supplementary Materials for dataset, notes, and funnel plots). For change in testosterone, we extracted effect sizes from analyses involving difference scores (time 2 - time 1), residuals (time 2 controlling statistically for time 1 ), or percent change scores [(time 2 - time 1) / time 1) * 100] ${ }^{1}$. For those studies reporting more than one post-task sample for determination of testosterone, all post-task correlations provided were averaged to give a single score. If one of the values above was not reported, we estimated effect sizes from one of the following methods: other statistics reported in the text (e.g., $t$ statistics from regression models, $F$ values and $d f$ from ANOVA) using Wilson's (2001) Effect Size Determination Program or the Psychometrica program for Computation of Effect Sizes (https://www.psychometrica.de/effect_size.html\#transform); direct correspondence with an author from the original study; extraction from available figures using WebPlotDigitizer (https://automeris.io/WebPlotDigitizer/). For studies that reported multiple indices of testosterone (e.g., free testosterone, total testosterone), we preferentially used free testosterone. For effect sizes from within-subject study designs (e.g., placebo-controlled cross-over designs), we used a correlation of $r=.50$ to represent the association between aggression measured pre- and post- drug administration $^{2}$. When available, sample size values were those reported by the original authors

\footnotetext{
${ }^{1}$ Although it is possible that these different calculation methods may produce different correlations with aggression, we have found extremely high correlations $(r \mathrm{~s}>.84)$ between these alternative calculation methods (reanalysis of Carré et al., 2013).

${ }^{2}$ Study design (within- versus between-subject manipulation of testosterone) was not a significant moderator in our analyses (see Results below), supporting our decision to combine effect sizes derived from these two types of designs in our meta-analyses.
} 
after participant exclusions. For group comparison effects, if sample sizes were not reported separately for groups, we assumed an even distribution of the sample (which sometimes resulted in a non-discrete value). When effect sizes for multiple measures of aggression (e.g., different questionnaires or subscales), multiple raters (e.g., self, parent, teacher), and/or testosterone (e.g., different sampling times, different measurement methods: saliva, blood; when participants were sober vs intoxicated) could be extracted for the same sample of participants, we used the average effect size across the measures or, if the sample size varied across measures because of missing data, the weighted mean. The largest $n$ for any given measure, however, was used for calculating the effect size's corresponding sampling variance. Three of the authors (JM, RP, and BMB) independently coded the sample sizes, moderator values, and effect sizes. After this initial coding was complete, the authors resolved any inconsistencies through discussion. For each study, the method for determining the effect size, as well as any relevant notes (e.g., potential deviations and reasons for deviation from the above methods) about determination of moderators, are reported in the Supplemental Materials.

\section{Moderator coding}

Year. The year of the publication was used as a proxy for the year the study was conducted.

Sex. Each effect size was coded for whether it was derived from males and/or females. Two studies reported effects for samples of men and women combined and did not provide estimates within each sex (Kopsida et al., 2016; Scerbo and Kolko, 1994); these samples were excluded from the analysis.

Age. We extracted the mean age of each sample or, if a range was reported, the midpoint of the range. If multiple sample ages were included, we calculated a weighted mean age for the effect size. If age was reported for an entire sample, but results reported separately for men and women, we used the same age value for both sexes.

Offender status. We coded whether the sample included offenders (i.e., was composed of either solely offenders or a mix of both offenders and non-offenders) or not. 
Method of testosterone determination. We coded whether testosterone was determined through saliva alone, or through a method that involved body fluids other than, or in addition to, saliva (e.g., urine, blood).

Time of testosterone determination. We coded whether the concentrations of testosterone were determined, in part, through collection methods involving afternoon times (12:00PM to 11:59PM) or exclusively morning times (12:00AM to 11:59PM).

Measure of aggression. We coded whether the aggression was determined through methods involving self-report questionnaires or not (e.g., through laboratory behavioural measures, the observations of behaviour, or criminal records indicating behaviour). Note that averages involving a self-report measure (in addition to a behavioural or observational measure) were coded as involving self-report.

Context of study. We coded whether the measures were collected exclusively in the laboratory or if some measures were collected outside of the laboratory (e.g., in the field; prison; school).

Country of study. We coded whether the study was conducted in U.S.A. or Canada versus elsewhere. When the country in which the data was collected was not reported, we used the country of the corresponding author's institution.

Analysis type. We coded whether the effect size was derived from a between-subject versus within-subject/correlational analysis.

\section{Statistical analyses}

Data were analysed using the metafor package (version 2.1-0, Viechtbauer, 2010) in $R$ (R Core Team, 2017) ${ }^{3}$. Given that there are likely many different true effect sizes across the different populations (men vs women, Canada/USA vs other countries, offender vs non-offenders) and

\footnotetext{
${ }^{3}$ The specific command was summary(model<-rma(ni=[total $n$ s for each effect size], ri=[r value for each effect], measure $=$ "ZCOR", data $=[$ dataframe name])). For models involving moderators, "mods $=\sim[$ first moderator $]+[$ second moderator]..." was added to the command. Effects were converted to Fisher's z scores for analysis (as indicated by "ZCOR" in the command) but were transformed back to $r$ values for tables, reporting, and figures. See analysis code in Supplementary Materials.
} 
contexts (e.g., when examined in the afternoon vs morning) examined here, we use random-effects modeling. Heterogeneity in effects were assessed using $I^{2}$ values and $Q$ statistics. $I^{2}$ values indicate the proportion of variability in effect sizes that can be attributed to systematic, between-study differences rather than within-study error (Higgins \& Thompson, 2002). $Q$ statistics—and their associated $p$ values — test whether such between-study difference is significant.

Given heterogeneity in the effect sizes (the baseline and the change models), we conducted separate meta-regressions testing each of the moderators individually (i.e., with the moderator of interest entered as the sole predictor in the model). When multiple moderators were identified as accounting for significant variability in the effect sizes, we examined the associations between the significant moderators; if they shared significant correlations, we ran follow-up meta-regressions in which these moderators were entered, as simultaneous predictors, within a single model. Regardless of significance, these meta-regression models allow us to estimate the relative and unique contribution of each moderator, over and above the influence of the other moderators in the model. Dichotomous moderators were coded with a one-unit distance between the two values. To interpret significant moderators, we ran follow-up meta-analyses within each of the levels of the moderator. For continuous moderators (year of study, age of participants), the model-generated estimates represent the change in effect size strength with every increasing year. To identify potential publication bias across our analyses, we conducted Egger's test of the regression intercept (Egger, Davey Smith, Schneider, \& Minder, 1997) and examined normal and counter-enhanced funnel plots; when Egger's tests were significant, we provided additional estimates of the effects after adjustments using trim and fill techniques (Duval \& Tweedie, 2000). We also estimated selection bias using Copas Selection Model Analysis (Copas, 1999; Copas \& Shi, 2000, 2001) included in the metasens package (Schwarzer, Carpenter \& Rücker, 2019), providing adjusted estimates of the overall effect size after accounting for potential missing, unpublished studies.

We also determined whether aggression shares stronger associations with changes in testosterone than with baseline concentrations within men and within women. Many studies that 
examined changes in testosterone, however, also reported correlations involving baseline testosterone; therefore, to avoid issues of non-independence of effects, we had to exclude these baseline effects from (only) these specific analyses comparing baseline and change models. In all other analyses involving baseline testosterone, these effects were included.

\section{Results \\ Do baseline levels of testosterone map onto variability in human aggression?}

Baseline testosterone was weakly but significantly associated with aggression $(r=0.064$, 95\% CIs $[0.035,0.094])$, although the effects were highly heterogenous $\left(Q_{117}=238.047, p<.001\right.$, $I^{2}=54.695 \%$ ) (the distribution of effect sizes was not asymmetrical, Egger's regression test: $z=$ 0.570, $p=0.569$, and Copas adjusted estimate did not differ). Two influential cases were identified, however, which appeared to be particularly strong given the corresponding sample sizes for the study (men: $r=.36, n=155$; women: $r=.41, n=151$, Harris et al., 1996). One potential reason the effects were so large from this manuscript is that the authors - unlike for other effect sizes included here-used canonical correlations, examining associations between sets of aggression-related variables and multiple measures of testosterone, rather than simpler associations between two individual variables. After excluding the effects, the association between baseline testosterone and aggression became slightly smaller $(r=0.054,95 \%$ CIs $[0.028,0.080])$, and effect sizes were less heterogeneous $\left(Q_{115}=204.211, p<.001, I^{2}=37.497 \%\right)$. Heterogeneity was explained by sex, with a stronger effect in men $(r=.071,95 \%$ CIs $[.041, .101])$ than women $(r=.002,95 \%$ CIs [-.041, .044]), publication year (older > newer studies), offender status (offenders > non-offenders), study context (outside > inside lab), and — albeit marginally significant — time of hormone determination (morning $>$ afternoon samples). See Table 1 for all moderator results and effect size estimates within each of the moderators' corresponding subgroups. Analysis type was also a significant moderator (between-subject $>$ within/correlational) but two large effects ( $r=.66$, Burnham, 2007; $r$ $=.75$, Ehrenkranz et al., 1974) appeared to be driving this effect; when these effects were removed, analysis type was no longer significant $(p=.147)$ but time of hormone determination became 
slightly stronger $(p=.045)$. Within the subgroups, the asymmetry in the distribution of effect sizes was minimal and non-significant (Egger's regression tests: $p$ s $>.120$; see Supplementary Materials for funnel plots), and there was minimal evidence of selection bias (Copas adjusted estimates did not differ from those provided in Table 1).

Some of the moderators were correlated; for example, older studies were more likely to involve offender samples $(r=.302)$, and both older studies and studies involving offender samples more likely to use morning testosterone sampling $(r \mathrm{~s}>.280)$ and to collect data outside of the laboratory (e.g., in the field, $r s>.280)(p s<.007)$. Therefore, we examined these correlated moderators as simultaneous predictors in a meta-regression model, allowing for the determination of each variable's unique contribution to explaining variability in effect sizes (sex was not included in this meta-regression given it was not correlated with any of the other significant moderators, $r$ s $<$ .14). In this meta-regression model, the only moderator that persisted was offender status (samples involving > not involving offenders) (see Table 1 for full results), suggesting that it largely carried the effects of the other moderators.

\section{Are acute changes in testosterone associated with variability in human aggression?}

Change in testosterone was positively correlated with aggression $(r=0.108,95 \% C I \mathrm{~s}$ $[0.041,0.174])$, although the effects were heterogenous $\left(Q_{30}=50.209, p=0.012, I^{2}=32.903 \%\right)$. The distribution of effect sizes was not asymmetrical (Egger's regression test: $z=1.551, p=0.121$ ) and Copas adjusted estimate did not substantially differ $(r=.107)$, providing limited evidence of publication/selection bias. This heterogeneity was explained by sex (men: $r=0.162,95 \%$ CIs [0.076, 0.246]; women: $r=0.010,95 \%$ CIs [-0.090, 0.109]). Publication year was also a significant moderator but appeared driven by a single effect size (with Klinesmith et al., 2006 removed, $p=$ $0.372)^{4}$. See Table 2 for all moderator results. The distribution of effect sizes in men was asymmetrical (Egger's regression test: $z=2.791, p=0.005)$; trim and fill $(r=0.151,95 \%$ CIs

\footnotetext{
${ }^{4}$ Aside from this moderation involving year, the removal of this effect (Klinesmith et al., 2006) did not change the pattern of results reported here.
} 
$[0.063,0.233])$ and Copas Selection Analysis $(r=0.120,95 \%$ CIs $[0.044,0.195])$ produced lower estimates. The distribution of effect sizes in women was not asymmetrical (Egger's regression test: $z=-1.102, p=0.271)$ and Copas adjusted estimate did not substantially differ $(r=.012)$. See Supplementary Materials for funnel plots.

Is the association between changes in testosterone and aggression stronger than that between baseline testosterone and aggression in men and/or women?

Within men, the association involving changes in testosterone was somewhat stronger (though not significantly) than the association involving baseline testosterone (estimate $=0.064$, 95\% CIs [-0.018, 0.145], $\mathrm{z}=1.538, p=0.124, k=91, n=12983)$. Within women, the strength of these associations did not differ (estimate $=0.007,95 \%$ CIs $[-0.102,0.117], \mathrm{z}=0.130, p=0.897, k$ $=31, n=2192)$. See Figure 1.

\section{Does administration of testosterone increase human aggression?}

Testosterone administration did not have an overall effect on aggression $(r=0.046,95 \%$ CIs $-0.015,0.108])$ and there was little, systematic, between-study difference in the effect sizes $\left(Q_{12}=\right.$ 4.667, $p=0.968$ ) (the distribution of effect sizes was not asymmetrical, Egger's regression test: $z=$ 0.262, $p=0.793$, Copas adjusted estimate did not differ). We nevertheless explored the moderator variables and the effect within men and women separately (see Table 3 for all moderator results). Within men $(r=0.055,95 \%$ CIs $[-0.013,0.122])$, the asymmetry in the distribution of effect sizes was minimal and non-significant (Egger's regression tests: $p=.983$; Copas adjusted estimate did not differ), suggesting limited evidence of publication bias. There were only two effect sizes in women $(r=0.012,95 \%$ CIs $[-0.140,0.163])$ and thus Egger's test and Copas Selection Model Analysis was not performed; see Supplementary Materials for funnel plots).

\section{Discussion}

Results from this updated meta-analysis are consistent with a prior meta-analysis (Archer et al., 2005) indicating that baseline testosterone concentrations are positively (yet weakly) correlated indices of human aggressive behaviour. In addition, we provide the first meta-analytic estimate 
indicating that context-dependent changes in testosterone concentrations are positively correlated with aggressive behaviour. Baseline and context-dependent changes in testosterone showed positive, yet relatively weak associations with aggression in males. In contrast, baseline and context-dependent changes in testosterone were unrelated to aggression in females. Despite positive associations between endogenous testosterone and aggression in men, we found no support for an effect of exogenous testosterone on aggressive behaviour.

\section{Baseline testosterone and human aggression}

The magnitude of the point estimate for the relationship between baseline testosterone and aggression was relatively small $(r=.054)$ and very similar to that previously reported $(r=.08$ : Archer et al., 2005). Archer et al. (2005) reported that the association between baseline testosterone and aggression was stronger in female $(r=.13)$ than in male samples $(r=.08)$. In the current metaanalysis, we found an opposite pattern whereby the correlation between baseline testosterone concentrations and aggression was significant in male $(r=.071)$ but not female samples $(r=.002)$. The association that we observed for males was remarkably similar to the point estimate reported by Archer et al. (2005), despite the current meta-analysis having nearly 2.5 times more effect sizes. In contrast, the correlation between baseline testosterone and female aggression was virtually nonexistent in the current meta-analysis. It is worth noting that the earlier meta-analysis included a relatively small number of effect sizes for females ( $k=8$ studies, $n=534)$. The point estimate was $r$ $=.13$, with the confidence interval suggesting that the effect size is anywhere from small (lower bound estimate, $r=.065$ ) to medium (upper bound estimate, $r=.191$ ) in magnitude. In the present meta-analysis, we were able to include a much larger number of effect sizes for females $(k=30$ studies, $n=2,334$ ), and results indicated that if there is a relationship between baseline testosterone and female aggression, it is very weak. If we optimistically estimate that the true relationship between baseline testosterone and female aggression is $r=.044$ (upper bound of confidence interval), a sample size of $n=3192$ would be needed to have $80 \%$ power to detect this effect. Similarly, if we optimistically estimate that the relationship between baseline testosterone and male 
aggression is $r=.101$ (upper bound of confidence interval), a sample size of $n=604$ would be needed to have $80 \%$ power to detect this effect. The average sample size associated with the effect sizes included in this meta-analysis is $n=117$ (note that when removing the largest sample size [Mazur \& Booth, 2014], the average sample size decreases to $n=87$ ). Therefore, previous research examining the relationship between baseline testosterone and human aggression is clearly underpowered to detect relatively small correlations revealed in the current meta-analysis.

\section{Acute testosterone changes and aggressive behaviour}

An important finding from behavioural endocrinology is that testosterone levels are not static, but rather fluctuate in the context of social interactions involving mating, competitive, and aggressive interactions (Wingfield et al., 1990; Archer, 2006). These findings have prompted some researchers to suggest that short-term changes in testosterone concentrations may be more relevant to individual differences in mating effort (including aggression) than baseline levels of testosterone (McGlothlin et al., 2007). Experimental work in some non-human animal models (e.g., mice, fish, birds) has found support for the idea that acute elevations in testosterone positively modulate competitive and aggressive behaviour (e.g., Trainor et al., 2004; Fuxjager et al., 2010; McGlothlin et al., 2007). In the past decade, several studies conducted with human participants have also found evidence that acute changes in testosterone during competitive interactions positively correlate with ongoing and/or future aggressive behaviour (see Carré \& Olmstead, 2015; Geniole \& Carré, 2018). In the current meta-analysis, acute changes in testosterone were indeed positively correlated with aggressive behaviour $(r=.108)$, with this relationship being moderated by sex. Specifically, the effect was significant in male $(r=.16)$, but not female samples $(r=.01)$. Although the association between change in testosterone and male aggression was more than twice the magnitude of the association between baseline testosterone and male aggression, this difference was not statistically significant $(p=.124)$.

If we optimistically estimate that the true relationship between change in testosterone and male aggression is $r=.246$ (upper bound of confidence interval), a sample size of $n=100$ would be 
needed to have $80 \%$ power to detect this effect. The average sample size for the studies in the metaanalysis involving change in testosterone in men is $n=47$. Therefore, similar to research on baseline testosterone concentrations, research examining the relationship between changes in testosterone and male aggression has been underpowered to detect relatively small-to-moderate correlations revealed in the current meta-analysis.

\section{Exogenous testosterone and aggressive behaviour}

Classic research in behavioural endocrinology, often using castration-replacement paradigms, clearly indicates that testosterone plays a role in modulating aggressive behaviour in many, though not all, species throughout vertebrates (see Nelson \& Trainor, 2007). One major limitation of research examining associations between endogenous testosterone (baseline and changes) and aggressive behaviour in humans is that it is correlational-leaving open the question as to whether testosterone plays a causal role in promoting aggression. To firmly establish causation requires an experimental approach in which testosterone concentrations are directly manipulated prior to the assessment of aggressive behaviour using either self-report and/or behavioural measures. Just over a dozen studies have directly examined effects of exogenous testosterone on self-report and behavioural indices of human aggression. Here, we find no evidence for an effect of exogenous testosterone on human aggression $(r=.046)$. However, it should be noted that the studies examined were highly heterogenous in terms of route of administration (injectable, transdermal, intranasal), dose used (supraphysiological vs. physiological), length of administration (single dose vs. chronic dosing), timing of behavioural assessment (shortly after dosing vs. several hours after dosing), and sex composition of the sample. All of these factors may influence the magnitude of the effect of testosterone on aggressive behaviour. However, there are too few studies $(k=14)$ to meaningfully examine the role of these factors in modulating the effect of exogenous testosterone on aggression. 


\section{Limitations}

Although the current meta-analysis provides an updated estimate of the relationship between testosterone and human aggression, there are some limitations that need to be highlighted. First, we did not include effect sizes from unpublished studies, and thus, the effect size estimates provided here may represent an overestimate of the effect size the relationship between testosterone (baseline, changes, and exogenous) and human aggression. Although examination of the funnel plots and Copas Selection Model Analysis did not provide compelling evidence for publication bias (with the exception of change in testosterone for men), we cannot exclude the possibility that null findings were under-represented in our meta-analysis due to publication bias.

The current meta-analysis is the first to examine associations between context-dependent changes in testosterone, exogenous testosterone and human aggression. A limitation of analyses involving testosterone dynamics is that the number of effect sizes reported (change in testosterone, $k=31$; exogenous testosterone, $k=14$ ) was relatively small, and thus, more work (with wellpowered studies) examining associations between testosterone dynamics and aggression will be needed.

Another limitation of this meta-analysis is that there was substantial heterogeneity in the measurement of aggression across the published studies. Although we coded for whether the studies involved behavioural or self-report measures, there was substantial variability even within behavioural and self-report measures. In light of the different forms of aggression (e.g., reactive vs. proactive; direct vs. indirect), future research may wish to examine the extent to which testosterone's association with aggression depends upon the form of aggression measured. Indeed, one study directly manipulated whether the aggression task elicited provocation or not and found that the association between changes in testosterone and aggression was strongest in the context of a provocative $(r=.16)$ versus a non-provocative $(r=.04)$ situation (see Carré et al., 2010).

\section{Future Directions}

Psychological, Genetic, and Contextual Moderators of the testosterone-aggression association 
Results from the current meta-analysis suggest that the association between testosterone (basal and reactivity) and human aggression is relatively weak. A number of recent studies have investigated the extent to which social context and/or personality traits moderate the relationship between testosterone and human aggression (see Carré \& Archer, 2018 for review). It is beyond the scope of this paper to provide an extensive review of all contextual and personality moderators however, we will briefly discuss trait dominance, impulsivity, and self-construal as they have been shown across both correlational and experimental studies to moderate associations between testosterone and outcomes conceptually linked to aggression. For instance, earlier correlational work found that baseline testosterone concentrations positively predicted dominance-related behaviour during a mating competition, but only among men scoring relatively high in trait dominance (Slatcher et al., 2011). Further, acute changes in testosterone in response to a competitive victory positively correlated with subsequent aggression, but only for men scoring relatively high in trait dominance (Carré et al., 2009). Going beyond correlational work, a single dose of testosterone increased competitive motivation after a victory, but only among women scoring relatively high in trait dominance (Mehta et al., 2015). Finally, a single dose of testosterone increased aggressive behaviour, but only among men scoring relatively high in trait dominance (Carré et al., 2017). Our research has also led us to examine the moderating role of self-construal which assesses the degree to which individuals construe the self in relation to others (Markus \& Kitayama, 1991). Independent people tend to view the self as independent of others, whereas interdependent people tend to view themselves as interconnected with others. Across two studies, acute changes in testosterone during a competitive interaction positively predicted subsequent aggressive behaviour, but only among men with independent self-construals (Welker et al., 2017). Lending more support to the moderating effect of self-construal was a recent experimental study demonstrating that administration of testosterone increased aggressive behaviour, but only for men scoring relatively high in independent self-construal (Geniole et al., 2019). Finally, we have also investigated the extent to which impulsivity moderates the effect of testosterone on human 
aggression. Specifically, across two pharmacological challenge experiments, we found that testosterone's potentiating effects on aggressive behaviour occurred exclusively among relatively impulsive men (Carré et al., 2017; Geniole et al., 2019). The finding that impulsivity moderates the effect of testosterone on human aggression is interesting in light of the current meta-analysis indicating that the association baseline testosterone and aggression was strongest among offenders - a group of individuals characterized by relatively high scores on indices of impulsivity (e.g., Arantes et al., 2013). Collectively, these results indicate that the personality traits of dominance, impulsivity, and self-construal are important variables to consider when examining associations between testosterone and human aggression.

In addition to personality traits, other work has focused on whether a polymorphism of the androgen receptor gene may influence the degree to which testosterone modulates physiological and behavioural processes relevant to human aggression. One functional polymorphism is the number of cytosine-adenine-guanine (CAG) repeats in exon 1 of the androgen receptor (AR) gene. Each triplet encodes the amino acid glutamine such that a greater number of CAG repeats leads to the production of androgen receptors with longer stretches of glutamine in the N-terminal domain. The functionality of this polymorphism has been confirmed in vitro whereby experimentally increasing the number of CAG repeats within the AR gene reduces the receptor's transcriptional potential (Chamberlain, Driver, \& Miesfeldi, 1994). Furthermore, in vivo work indicates that endogenous testosterone concentrations positively modulate threat-related amygdala function (Manuck et al., 2010) and self-reported aggressive behaviour (Vermeersch et al., 2010) — but only among men with relatively fewer CAG repeats within the AR gene. We have confirmed this pattern of findings in a recent pharmacological challenge study $(n=306)$ whereby exogenous testosterone increased aggressive behaviour - but only among men with relatively fewer CAG repeats on the AR gene (Geniole et al., 2019). Moreover, we found that previously reported testosterone X personality interactions (i.e., testosterone $\mathrm{X}$ trait dominance; testosterone $\mathrm{X}$ impulsivity; see Carré et al., 2017) were stronger among men with fewer (vs more) CAG repeats on the AR gene (Geniole et al., 2019). 
In addition to personality traits and AR genotype, some work suggests that social context may influence the degree to which testosterone reactivity to social interactions predict male aggression. Broadly speaking (and without a large enough sample size to perform formal moderation analyses), associations between testosterone responses to social interactions and aggression (or dominance-related outcomes) appear strongest among losers versus winners of competitions (Carré et al., 2009; Metha \& Josephs, 2006; Mehta et al., 2015) and for people who have been provoked versus unprovoked (Carré et al., 2010). The contextual moderators may share a common feature — specifically, increased threat to one's social status.

\section{Testing causal mechanisms in both male and female samples}

Until approximately 10 years ago (see Zak et al., 2009), single dose testosterone administration studies were conducted almost exclusively in female samples (see Bos et al., 2012 for review). In the past decade, pharmacological challenge probes involving single dose transdermal (Eisenegger et al., 2013), injectable (Dreher et al., 2016), and intranasal (Geniole et al., 2019) testosterone have been developed for use in healthy young males. Nevertheless, more work is needed comparing the effects of testosterone administration to both men and women within the same study design. Importantly, however, such a design should also adjust dosing such that increases in men and women are of a similar percentage, relative to their sex-specific baseline concentrations. Currently, for example, most work in women utilizes sublingual testosterone $(0.5$ mg) administration, resulting in concentrations 2,000\% above baseline (van Rooij et al., 2012) whereas recent single-dose studies in men have boosted concentrations 50-100\% above baseline (Eisenegger et al., 2013; Carré et al., 2017; Geniole et al., 2019). Thus, a direct comparison of the effects of testosterone on male and female aggression should consider using pharmacological challenge protocols that yield a similar proportional rise in testosterone, otherwise sex-specific effects may be obscured or confounded by relative dose-dependent effects [such as those discovered with oxytocin, where moderate (relative to low or high) doses more strongly reduce amygdala reactivity to fear-related stimuli in men (Spengler et al., 2017)]. Therefore, consideration of dosing 
and the design of challenge protocols that produce similar proportional rises in testosterone in males and females should be considered when examining potential sex-dependent effects of testosterone on human aggression.

\section{Conclusion}

In summary, our updated meta-analysis on the association between testosterone and human aggression reveals that associations between endogenous testosterone and aggressive behaviour are relatively weak and moderated by sex (baseline and acute changes) and offender status (baseline testosterone). Results from exogenous testosterone administration work did not provide compelling evidence for a causal role of testosterone in promoting aggression. However, the latter findings are limited by the substantial heterogeneity in methods used in testosterone manipulation studies. An important "take home message" from this meta-analysis is that relationships between testosterone and human aggression are relatively weak, and thus, more well-powered samples will be needed to provide sufficient statistical power to detect such small effects. In addition, more research will be needed that examines contextual and psychological moderators of the relationship between testosterone and aggression. Correlational and experimental research has yielded some evidence for moderator effects (e.g., trait dominance, impulsivity, self-construal; see Slatcher et al., 2011; Carré et al., 2009; Carré et al., 2017; Welker et al., 2017; Geniole et al., 2019). Such effects need to be independently replicated using large sample sizes to further our understanding of the degree to which such factors play a role in determining the people for whom, and circumstances under which, testosterone ultimately modulates human aggressive behaviour.

\section{Acknowledgments}

This work was supported by a Discovery Grant from the Natural Sciences and Engineering Research Council of Canada (RGPIN-2014-06676) and an Early Researcher Award from the Ontario Ministry of Research and Innovation to JMC. SNG holds a Banting Postdoctoral Fellowship from the Social Sciences and Humanities Research Council (SSHRC) of Canada. 


\section{References}

*Aluja, A., \& Torrubia, R. (2004). Hostility-aggressiveness, sensation seeking, and sex hormones in men: Re-exploring their relationship. Neuropsychobiology, , 50(1), 102-107 https://doi.org/10.1159/000077947

Arantes, J., Berg, M.E., Lawlor, D., \& Grace, R.C. (2013). Offenders have higher delay-discounting rates than non-offenders after controlling for differences in drug and alcohol abuse. Legal and Criminological Psychology, 18, 240-253. http://doi.org/10.1111/j.20448333.2012.02052.x

Archer, J. (2006). Testosterone and human aggression: An evaluation of the Challenge Hypothesis. Neuroscience \& Biobehavioral Reviews, 30(3), 319-345. http://doi.org/10.1016/j.neubiorev.2004.12.007

Archer, J. (2009). Does sexual selection explain human sex differences in aggression? Behavioral and Brain Sciences, 32(3-4), 249-66; discussion 266-311. http://doi.org/10.1017/S0140525X09990951

*Archer, J., Birring, S. S., \& Wu, F. C. W. (1998). The association between testosterone and aggression among young men: Empirical findings and a meta-analysis. Aggressive Behavior, 24(6), 411-420. https://doi.org/10.1002/(SICI)1098-2337(1998)24:6<411::AID-

\section{$\mathrm{AB} 2>3.0 . \mathrm{CO} ; 2-9$}

Archer, J., Graham-Kevan, N., \& Davies, M. (2005). Testosterone and aggression: A reanalysis of Book, Starzyk, and Quinsey's (2001) study. Aggression and Violent Behavior, 10(2), 241-261. http://doi.org/10.1016/j.avb.2004.01.001

*Azurmendi, A., Braza, F., García, A., Braza, P., Muñoz, J. M., \& Sánchez-Martín, J. R. (2006). Aggression, dominance, and affiliation: Their relationships with androgen levels and intelligence in 5-year-old children. Hormones and Behavior, 50, 132-140. https://doi.org/10.1016/j.yhbeh.2006.02.004 
*Bain, J., Langevin, R., Dickey, R., \& Ben-Aron, M. (1987). Sex hormones in murderers and assaulters. Behavioral Sciences \& the Law, 5(1), 95-101. http://doi.org/10.1002/bs1.2370050109

*Banks, T., \& Dabbs, J. M. (1996). Salivary testosterone and cortisol in a delinquent and violent urban subculture. Journal of Social Psychology, 136(1), 49-56. https://doi.org/10.1080/00224545.1996.9923028

Baron, R. A., \& Richardson, D. R. (1994). Human Aggression (2nd ed.). New York, NY: Plenum Press.

Baumeister, R. F., Vohs, K. D., \& Funder, D. C. (2007). Psychology as the Science of Self-Reports and Finger Movements: Whatever Happened to Actual Behavior? Perspectives on Psychological Science, 2(4), 396-403. http://doi.org/10.1111/j.1745-6916.2007.00051.x

*Beeman, E. A. (1947). The effect of male hormone on aggressive behavior in mice. Physiological Zoology, 20(4), 373-405.

*Berman, M., Gladue, B., \& Taylor, S. (1993). The effects of hormones, Type A behavior pattern, and provocation on aggression in men. Motivation and Emotion, 17(2), 125-138. https://doi.org/10.1007/BF00995189

Berthold, A. A., \& Quiring, D. P. (1944). The transplantation of testes: translated by D.P. Quiring. Bulletin of the History of Medicine, 16, 399-401.

Bettencourt, B. A., \& Kernahan, C. (1997). A Meta-Analysis of Aggression in the Presence of Violent Cues: Effects of Gender Differences and Aversive Provocation. Aggressive Behavior, 23(6), 447-456.

Bettencourt, B. A., \& Miller, N. (1996). Gender differences in aggression as a function of provocation: a meta-analysis. Psychological Bulletin, 119(3), 422-447.

*Borráz-León, J. I., Cerda-Molina, A. L., Rantala, M. J., \& Mayagoitia-Novales, L. (2018). Choosing Fighting Competitors Among Men: Testosterone, Personality, and Motivations. Evolutionary Psychology, 16(1), 1-10. https://doi.org/10.1177/1474704918757243. 
Bos, P.A., Panksepp, J., Bluthé, R.M., \& van Honk, J. (2012). Acute effects of steroid hormones and neuropeptides on human social-emotional behavior: A review of single administration studies. Frontiers in Neuroendocrinology, 33, 17-35. https:// doi:10.1016/j.yfrne.2011.01.002.

*Brooks, J. H., \& Reddon, J. R. (1996). Serum testosterone in violent and nonviolent young offenders. Journal of Clinical Psychology, 52(4), 475-483. https://doi.org/10.1002/(SICI)10974679(199607)52:4<475::AID-JCLP14>3.0.CO;2-D

*Burnham, T. C. (2007). High-testosterone men reject low ultimatum game offers. Proceedings of the Royal Society B: Biological Sciences, 274(1623), 2327-2330.

https://doi.org/10.1098/rspb.2007.0546

*Campbell, A., Muncer, S., \& Odber, J. (1997). Aggression and testosterone: Testing a bio-social model. Aggressive Behavior, 23, 229-238. https://doi.org/10.1002/(SICI)10982337(1997)23:4<229::AID-AB1>3.0.CO;2-F

Carré, J. M., \& Archer, J. (2018). Testosterone and human behavior: the role of individual and contextual variables. Current Opinion in Psychology, 19, 149-153. http://doi.org/10.1016/j.copsyc.2017.03.021

*Carré, J. M., Baird-Rowe, C. D., \& Hariri, A. R. (2014). Testosterone responses to competition predict decreased trust ratings of emotionally neutral faces. Psychoneuroendocrinology, 49, 79-83. https://doi.org/10.1016/j.psyneuen.2014.06.011

*Carré, J. M., Campbell, J. A., Lozoya, E., Goetz, S. M. M., \& Welker, K. M. (2013). Changes in testosterone mediate the effect of winning on subsequent aggressive behaviour. Psychoneuroendocrinology, 38, 2034-2041. http://doi.org/10.1016/j.psyneuen.2013.03.008

*Carré, J. M., Geniole, S. N., Ortiz, T. L. T. L., Bird, B. M. B. M., Videto, A., \& Bonin, P. L. P. L. (2017). Exogenous testosterone rapidly increases aggressive behavior in dominant and impulsive men. Biological Psychiatry, 82(4), 249-256. http://doi.org/10.1016/j.biopsych.2016.06.009

*Carré, J. M., Gilchrist, J. D., Morrissey, M. D., \& McCormick, C. M. (2010). Motivational and 
situational factors and the relationship between testosterone dynamics and human aggression during competition. Biological Psychology, 84(2), 346-353.

http://doi.org/10.1016/j.biopsycho.2010.04.001

*Carré, J. M., Iselin, A. M. R., Welker, K. M., Hariri, A. R., \& Dodge, K. A. (2014). Testosterone Reactivity to Provocation Mediates the Effect of Early Intervention on Aggressive Behavior. Psychological Science, 25(5), 1140-1146. https://doi.org/10.1177/0956797614525642

*Carré, J. M., \& McCormick, C. M. (2008). Aggressive behavior and change in salivary testosterone concentrations predict willingness to engage in a competitive task. Hormones and Behavior, 54(3), 403-409. https://doi.org/10.1016/j.yhbeh.2008.04.008

Carré, J. M., \& Olmstead, N. A. (2015). Social neuroendocrinology of human aggression: Examining the role of competition-induced testosterone dynamics. Neuroscience, 286, 171186. https://doi.org/10.1016/j.neuroscience.2014.11.029

*Carré, J. M., Putnam, S. K., \& McCormick, C. M. (2009). Testosterone responses to competition predict future aggressive behaviour at a cost to reward in men. Psychoneuroendocrinology, 34(4), 561-570. http://doi.org/10.1016/j.psyneuen.2008.10.018

Chamberlain, N. L., Driver, E. D., \& Miesfeld, R. L. (1994). The length and location of CAG trinucleotide repeats in the androgen receptor $\mathrm{N}$-terminal domain affect transactivation function. Nucleic Acids Research, 22, 3181-3186. https://doi.org/10.1093/nar/22.15.3181

*Christiansen, K., \& Knussmann, R. (1987). Androgen levels and components of aggressive behavior in men. Hormones and Behavior, 21, 170-180. https://doi.org/10.1016/0018$506 X(87) 90042-0$

Copas J (1999): What works? Selectivity models and meta-analysis. Journal of the Royal Statistical Society, Series A, 162, 95-109.

Copas J, Shi JQ (2000): Meta-analysis, funnel plots and sensitivity analysis. Biostatistics, 1, 24762.

Copas JB, Shi JQ (2001): A sensitivity analysis for publication bias in systematic reviews. 
Statistical Methods in Medical Research, 10, 251-65.

*Cote, K. A., McCormick, C. M., Geniole, S. N., Renn, R. P., \& MacAulay, S. D. (2013). Sleep deprivation lowers reactive aggression and testosterone in men. Biological Psychology, 92, 249-256. https://doi.org/10.1016/j.biopsycho.2012.09.011

*Cueva, C., Roberts, R. E., Spencer, T. J., Rani, N., Tempest, M., Tobler, P. N., ... Rustichini, A. (2017). Testosterone administration does not affect men's rejections of low ultimatum game offers or aggressive mood. Hormones and Behavior, 87, 1-7. https://doi.org/10.1016/j.yhbeh.2016.09.012

*Dabbs, J. M., Carr, T. S., Frady, R. L., \& Riad, J. K. (1995). Testosterone, crime, and misbehavior among 692 male prison inmates. Personality and Individual Differences, 18(5), 627-623. https://doi.org/10.1016/0191-8869(94)00177-T

*Dabbs, J. M., \& Hargrove, M. F. (1997). Age, testosterone, and behavior among female prison inmates. Psychosomatic Medicine, 59(5), 477-480. https://doi.org/10.1097/00006842199709000-00003

*Dabbs, J. M., Hopper, C. H., \& Jurkovic, G. J. (1990). Testosterone and personality among college students and military veterans. Personality and Individual Differences, 11(12), 1263-1269. https://doi.org/10.1016/0191-8869(90)90153-I

*Dabbs, J. M., Jurkovic, G. J., \& Frady, R. L. (1991). Salivary testosterone and cortisol among late adolescent male offenders. Journal of Abnormal Child Psychology, 19(4), 469-478. https://doi.org/10.1007/BF00919089

*Dabbs, J. M., Ruback, R. B., Frady, R. L., Hopper, C. H., \& Sgoutas, D. S. (1988). Saliva testosterone and criminal violence among women. Personality and Individual Differences, 9(2), 269-275. https://doi.org/10.1016/0191-8869(88)90088-8

Daly, M., \& Wilson, M. (1988). Homicide. (S. B. Hrdy \& R. W. Wrangham, Eds.). New York, NY: Aldine de Gruyter.

*Denson, T. F., Mehta, P. H., \& Ho Tan, D. (2013). Endogenous testosterone and cortisol jointly 
influence reactive aggression in women. Psychoneuroendocrinology, 38(3), 416-424. https://doi.org/10.1016/j.psyneuen.2012.07.003

*Diekhof, E. K., Wittmer, S., \& Reimers, L. (2014). Does competition really bring out the worst? testosterone, social distance and inter-male competition shape parochial altruism in human males. PLoS ONE, 9(7). https://doi.org/10.1371/journal.pone.0098977

*Dougherty, D. M., Bjork, J. M., Moeller, F. G., \& Swann, A. C. (1997). The influence of menstrual-cycle phase on the relationship between testosterone and aggression. Physiology and Behavior. 62(2), 431-435. https://doi.org/10.1016/S0031-9384(97)88991-3

*Dreher, J.-C., Dunne, S., Pazderska, A., Frodl, T., Nolan, J. J., \& O’Doherty, J. P. (2016). Testosterone causes both prosocial and antisocial status-enhancing behaviors in human males. Proceedings of the National Academy of Sciences, 113(41), 11633-11638. https://doi.org/10.1073/pnas.1608085113

*Ehrenkranz, J., Bliss, E., Sheard, M.H. (1974). Plasma testosterone: Correlation with aggressive behavior and social dominance in man. Psychosom Medicine, 36, 469-75.

*Eisenegger, C., Naef, M., Snozzi, R., Heinrichs, M., \& Fehr, E. (2010). Prejudice and truth about the effect of testosterone on human bargaining behaviour. Nature, 463(7279), 356-359. http://doi.org/10.1038/nature08711

*Eriksson, C. J. P., von der Pahlen, B., Sarkola, T., \& Seppä, K. (2003). Oestradiol and human male alcohol-related aggression. Alcohol and Alcoholism, 38(6), 589-596. https://doi.org/10.1093/alcalc/agg117

Fuxjager, M. J., \& Marler, C. A. (2010). How and why the winner effect forms: Influences of contest environment and species differences. Behavioral Ecology, 21(1), 37-45. https://doi.org/10.1093/beheco/arp148

*Geniole, S. N., Busseri, M. A., \& McCormick, C. M. (2013). Testosterone dynamics and psychopathic personality traits independently predict antagonistic behavior towards the perceived loser of a competitive interaction. Hormones and Behavior, 64(5), 790-798. 
https://doi.org/10.1016/j.yhbeh.2013.09.005

Geniole, S. N., \& Carré, J. M. (2017). Hierarchy and testosterone: How can testosterone promote upward mobility in status hierarchies? In L. L. M. Welling \& T. K. Shackelford (Eds.), Oxford Handbook on Evolutionary Psychology and Behavioral Endocrinology. New York, NY: Oxford University Press.

Geniole, S. N., \& Carré, J. M. (2018). Human social neuroendocrinology: Review of the rapid effects of testosterone. Hormones and Behavior, 104, 192-205. http://doi.org/10.1016/j.yhbeh.2018.06.001

*Geniole, S. N., Carré, J. M., \& McCormick, C. M. M. (2011). State, not trait, neuroendocrine function predicts costly reactive aggression in men after social exclusion and inclusion. Biological Psychology, 87(1), 137-45. http://doi.org/10.1016/j.biopsycho.2011.02.020

*Geniole, S. N., Procyshyn, T. L., Marley, N., Ortiz, T. L., Bird, B. M., Marcellus, A. L., ... Carré, J. M. (2019). Using a psychopharmacogenetic approach to identify the pathways through which - and the people for whom - testosterone promotes aggression. Psychological Science, 30(4), 481-494. http://doi.org/10.1177/0956797619826970

*Gladue, B. A. (1991). Aggressive behavioral characteristics, hormones, and sexual orientation in men and women. Aggressive Behavior, 17(6), 313-326. https://doi.org/10.1002/10982337(1991)17:6<313::AID-AB2480170603>3.0.CO;2-Z

*Gray, A., Jackson, D. N., \& McKinlay, J. B. (1991). The relation between dominance, anger, and hormones in normally aging men: Results from the Massachusetts male aging study. Psychosomatic Medicine, 53(4), 375-385. https://doi.org/10.1097/00006842-199107000-00003

Greitemeyer, T., \& Sagioglou, C. (2016). Subjective socioeconomic status causes aggression: A test of the theory of social deprivation. Journal of Personality and Social Psychology, 111(2), 178194. http://doi.org/10.1037/pspi0000058

*Grotzinger, A. D., Mann, F. D., Patterson, M. W., Tackett, J. L., Tucker-Drob, E. M., \& Harden, K. P. (2018). Hair and Salivary Testosterone, Hair Cortisol, and Externalizing Behaviors in 
Adolescents. Psychological Science, 29(5), 688-699.

https://doi.org/10.1177/0956797617742981

Groves, C. L., \& Anderson, C. A. (2018). Aversive events and aggression. Current Opinion in Psychology, 19, 144-148. http://doi.org/10.1016/j.copsyc.2017.03.027

*Halpern, C. T., Udry, J. R., Campbell, B., \& Suchindran, C. (2010). Relationships between aggression and pubertal increases in testosterone: A panel analysis of adolescent males. Biodemography and Social Biology, 40(1-2), 8-24. https://doi.org/10.1080/19485565.1993.9988832

*Handelsman, D. J., Sikaris, K., \& Ly, L. P. (2016). Estimating age-specific trends in circulating testosterone and sex hormone-binding globulin in males and females across the lifespan. Annals of Clinical Biochemistry, 53(3), 377-384. http://doi.org/10.1177/0004563215610589

*Harris, J. A., Rushton, J. P., Hampson, E., \& Jackson, D. N. (1996). Salivary testosterone and selfreport aggressive and pro-social personality characteristics in men and women. Aggressive Behavior, 22(5), 321-331. https://doi.org/10.1002/(SICI)1098-2337(1996)22:5<321::AID$\mathrm{AB} 1>3.0 . \mathrm{CO} ; 2-\mathrm{M}$

Hershcovis, M. S., Turner, N., Barling, J., Arnold, K. A., Dupré, K. E., Inness, M., ... Sivanathan, N. (2007). Predicting workplace aggression: A meta-analysis. Journal of Applied Psychology, 92(1), 228-238. http://doi.org/10.1037/0021-9010.92.1.228

Higgins, J. P. T., \& Thompson, S. G. (2002). Quantifying heterogeneity in a meta-analysis. Statistics in Medicine, 21(11), 1539-1558. http://doi.org/10.1002/sim.1186

*Houser, B. B. (1979). An investigation of the correlation between hormonal levels in males and mood, behavior and physical discomfort. Hormones and Behavior, 12(2), 185-197. https://doi.org/10.1016/0018-506X(79)90020-5

*Inoue, Y., Takahashi, T., Burriss, R. P., Arai, S., Hasegawa, T., Yamagishi, T., \& Kiyonari, T. (2017). Testosterone promotes either dominance or submissiveness in the Ultimatum Game depending on players' social rank. Scientific Reports, 7(5335), 1-9. 
https://doi.org/10.1038/s41598-017-05603-7

Jones, S. E., Miller, J. D., \& Lynam, D. R. (2011). Personality, antisocial behavior, and aggression: A meta-analytic review. Journal of Criminal Justice, 39(4), 329-337. http://doi.org/10.1016/j.jcrimjus.2011.03.004

*Kingston, D. A., Seto, M. C., Ahmed, A. G., Fedoroff, P., Firestone, P., \& Bradford, J. M. (2012). The role of central and peripheral hormones in sexual and violent recidivism in sex offenders. The Journal of the American Academy of Psychiatry and the Law, 40(4), 476-485.

*Klinesmith, J., Kasser, T., \& McAndrew, F. T. (2006). Guns, testosterone, and aggression: an experimental test of a mediational hypothesis. Psychological Science, 17(7), 568-71. http://doi.org/10.1111/j.1467-9280.2006.01745.x

*Kopsida, E., Berrebi, J., Petrovic, P., \& Ingvar, M. (2016). Testosterone administration related differences in brain activation during the Ultimatum Game. Frontiers in Neuroscience, 10(66), 1-11. https://doi.org/10.3389/fnins.2016.00066

*Kreuz, L. E., \& Rose, R. M. (1972). Assessment of aggressive behavior and plasma testosterone in a young criminal population. Psychosomatic Medicine, 34(4), 321-332. http://doi.org/10.1097/00006842-197207000-00006

*Lindman, R., von der Pahlen, B., Öst, Bj., \& Eriksson, C. J. P. (1992). Serum testosterone, cortisol, glucose, and ethanol in males arrested for spouse abuse. Aggressive Behavior, 18(6), 393-400. https://doi.org/10.1002/1098-2337(1992)18:6<393::AID-AB2480180602>3.0.CO;2$\mathrm{N}$

*Lobbestael, J., Baumeister, R. F., Fiebig, T., \& Eckel, L. A. (2014). The role of grandiose and vulnerable narcissism in self-reported and laboratory aggression and testosterone reactivity. Personality and Individual Differences, 69, 22-27. https://doi.org/10.1016/j.paid.2014.05.007

Lobbestael, J. (2015). Challenges in aggression assessment: The gap between self-report and behavior, and a call for new valid behavioral paradigms. Journal of Socialomics, 5(1), 5-6. http://doi.org/10.4172/2167-0358.1000141 
Manuck, S. B., Marsland, A. L., Flory, J. D., Gorka, A., Ferrell, R. E., \& Hariri, A. R. (2010). Salivary testosterone and a trinucleotide (CAG) length polymorphism in the androgen receptor gene predict amygdala reactivity in men. Psychoneuroendocrinology, 35(1), 94-104. https://doi.org/10.1016/j.psyneuen.2009.04.013

Markus, H. R., \& Kitayama, S. (1991). Culture and the self: Implications for cognition, emotion, and motivation. Psychological Review, 98(2), 224-253. https://doi.org/10.1037/0033295X.98.2.224

*Mattsson, Å., Schalling, D., Olweus, D., Löw, H., \& Svensson, J. (1980). Plasma Testosterone, Aggressive Behavior, and Personality Dimensions in Young Male Delinquents. Journal of the American Academy of Child Psychiatry, 19(3), 476-490. https://doi.org/10.1016/S00027138(09)61065-7

*Mazur, A., \& Booth, A. (2014). Testosterone is related to deviance in male army veterans, but relationships are not moderated by cortisol. Biological Psychology, 96, 72-76. https://doi.org/10.1016/j.biopsycho.2013.11.015

McGlothlin, Jodie M. Jawor, \& Ketterson. (2017). Natural Variation in a Testosterone-Mediated Trade-off between Mating Effort and Parental Effort. The American Naturalist, 170(6), 864875. https://doi.org/10.2307/4541160

*Mehta, P. H., \& Beer, J. (2010). Neural mechanisms of the testosterone-aggression relation: The role of orbitofrontal cortex. Journal of Cognitive Neuroscience, 22(10), 2357-2368. https://doi.org/10.1162/jocn.2009.21389

*Mehta, P. H., Mor, S., Yap, A. J., \& Prasad, S. (2015). Dual-Hormone Changes Are Related to Bargaining Performance. Psychological Science, 26(6), 866-876. https://doi.org/10.1177/0956797615572905

*Mehta, P. H., Snyder, N. A., Knight, E. L., \& Lassetter, B. (2015). Close Versus Decisive Victory Moderates the Effect of Testosterone Change on Competitive Decisions and Task Enjoyment. Adaptive Human Behavior and Physiology, 1(3), 291-311. https://doi.org/10.1007/s40750-014- 
0014-0

*Meyer-Bahlburg, H. F. L., Nat, R., Boon, D. A., Sharma, M., \& Edwards, J. A. (1974).

Aggressiveness and Testosterone Measures in Man. Psychosomatic Medicine, 36(3), 269-274. https://doi.org/10.1097/00006842-197405000-00010

*Monti, P. M., Brown, W. A., \& Corriveau, D. P. (1977). Testosterone and components of aggressive and sexual behavior in man. American Journal of Psychiatry, 134(6), 692-694. https://doi.org/10.1176/ajp.134.6.692

Nelson, R. J., \& Trainor, B. C. (2007). Neural mechanisms of aggression. Nature Reviews Neuroscience, 8(7), 536-546. https://doi.org/10.1038/nrn2174

Norman, R. E., Moreau, B. J. P., Welker, K. M., \& Carré, J. M. (2014). Trait anxiety moderates the relationship between testosterone responses to competition and aggressive behavior. Adaptive Human Behavior and Physiology, 1, 312-324. http://doi.org/10.1007/s40750-014-0016-y

*O’Connor, D. B., Archer, J., Hair, W. M., \& Wu, F. C. W. (2002). Exogenous testosterone, aggression, and mood in eugonadal and hypogonadal men. Physiology and Behavior, 75(4), 557-566. http://doi.org/10.1016/S0031-9384(02)00647-9

*O'Connor, D. B., Archer, J., \& Wu, F. C. W. (2004). Effects of testosterone on mood, aggression, and sexual behavior in young men: A double-blind, placebo-controlled, cross-over study. The Journal of Clinical Endocrinology \& Metabolism, 89(6), 2837-2845.

http://doi.org/10.1210/jc.2003-031354

*Oliveira, T., Gouveia, M. J., \& Oliveira, R. F. (2009). Testosterone responsiveness to winning and losing experiences in female soccer players. Psychoneuroendocrinology, 34(7), 1056-1064. https://doi.org/10.1016/j.psyneuen.2009.02.006

*Olweus, D., Mattsson, Å., Schalling, D., \& Low, H. (1980). Testosterone, aggression, physical, and personality dimensions in normal adolescent males. Psychosomatic Medicine, 42(2), 253-269. https://doi.org/10.1097/00006842-198003000-00003

*Orengo, C. A., Kunik, M. E., Ghusn, H., \& Yudofsky, S. C. (1997). Correlation of testosterone 
with aggression in demented elderly men. Journal of Nervous and Mental Disease, 185(5), 349-351. https://doi.org/10.1097/00005053-199705000-00012

*Oxford, J. K., Tiedtke, J. M., Ossmann, A., Özbe, D., \& Schultheiss, O. C. (2017). Endocrine and aggressive responses to competition are moderated by contest outcome, gender, individual versus team competition, and implicit motives. PLoS ONE, 12(7), e0181610. https://doi.org/10.1371/journal.pone.0181610

*Panagiotidis, D., Clemens, B., Habel, U., Schneider, F., Schneider, I., Wagels, L., \& Votinov, M. (2017). Exogenous testosterone in a non-social provocation paradigm potentiates anger but not behavioral aggression. European Neuropsychopharmacology, 27(11), 1172-1184. http://doi.org/10.1016/j.euroneuro.2017.07.006

*Pascual-Sagastizabal, E., Azurmendi, A., Braza, F., Vergara, A. I., Cardas, J., \& Sánchez-Martín, J. R. (2014). Parenting styles and hormone levels as predictors of physical and indirect aggression in boys and girls. Aggressive Behavior, 40(5), 465-473. https://doi.org/10.1002/ab.21539

*Peper, J. S., De Reus, M. A., Van Den Heuvel, M. P., \& Schutter, D. J. L. G. (2015). Short fused? associations between white matter connections, sex steroids, and aggression across adolescence. Human Brain Mapping, 36(3), 1043-1052. https://doi.org/10.1002/hbm.22684

*Persky, H., Smith, K. D., \& Basu, G. K. (1971). Relation of psychologic measures of aggression and hostility to testosterone production in man. Psychosomatic Medicine, 33(3), 265-278. http://doi.org/10.1097/00006842-197105000-00007

*Platje, E., Popma, A., Vermeiren, R. R. J. M., Doreleijers, T. A. H., Meeus, W. H. J., van Lier, P. A. C., ... Jansen, L. M. C. (2015). Testosterone and cortisol in relation to aggression in a nonclinical sample of boys and girls. Aggressive Behavior, 41(5), 478-487. https://doi.org/10.1002/ab.21585

*Popma, A., Vermeiren, R., Geluk, C. A. M. L., Rinne, T., van den Brink, W., Knol, D. L., ... Doreleijers, T. A. H. (2007). Cortisol Moderates the Relationship between Testosterone and 
Aggression in Delinquent Male Adolescents. Biological Psychiatry, 61(3), 405-411. https://doi.org/10.1016/j.biopsych.2006.06.006

*Pope, H. G., Kouri, E. M., \& Hudson, J. I. (2000). Effects of supraphysiologic doses of testosterone on mood and aggression in normal men. Archives of General Psychiatry, 57, 133140.

*Portnoy, J., Raine, A., Glenn, A. L., Chen, F. R., Choy, O., \& Granger, D. A. (2015). Digit ratio (2D:4D) moderates the relationship between cortisol reactivity and self-reported externalizing behavior in young adolescent males. Biological Psychology, 112, 94-106. https://doi.org/10.1016/j.biopsycho.2015.09.013

R Core Team. (2017). R: A language and environment for statistical computing. Vienna, Austria: R Foundation for Statistical Computing.

*Reimers, L., Büchel, C., \& Diekhof, E. K. (2017). Neural substrates of male parochial altruism are modulated by testosterone and behavioral strategy. Neuroimage, 156, 265276.https://doi.org/10.1016/j.neuroimage.2017.05.033

*Ribeiro, E., Neave, N., Morais, R. N., Kilduff, L., Taylor, S. R., Butovskaya, M., .. Manning, J. T. (2016). Digit ratio (2D:4D), testosterone, cortisol, aggression, personality and hand-grip strength: Evidence for prenatal effects on strength. Early Human Development, 100, 21-25. https://doi.org/10.1016/j.earlhumdev.2016.04.003

*Romero-Martínez, Á., Lila, M., Sariñana-González, P., González-Bono, E., \& Moya-Albiol, L. (2013). High testosterone levels and sensitivity to acute stress in perpetrators of domestic violence with low cognitive flexibility and impairments in their emotional decoding process: A preliminary study. Aggressive Behavior, 39(5) 355-369. https://doi.org/10.1002/ab.21490

*Ryan, S. R., Brennan, P. A., Cunningham, P. B., Foster, S. L., Brock, R. L., \& Whitmore, E. (2013). Biosocial processes predicting multisystemic therapy treatment response. Biological Psychology, 92(2), 373-379. https://doi.org/10.1016/j.biopsycho.2012.12.002 
*Salvador, A., Suay, F., Martinez-Sanchis, S., Simon, V. M., \& Brain, P. F. (1999). Correlating testosterone and fighting in male participants in judo contests. Physiology and Behavior, 68(1-2), 205-209. https://doi.org/10.1016/S0031-9384(99)00168-7

*Sánchez-Martín, J. R., Fano, E., Ahedo, L., Cardas, J., Brain, P. F., \& Azpíroz, A. (2000).

Relating testosterone levels and free play social behavior in male and female preschool children. Psychoneuroendocrinology, 25(8), 773-783.. https://doi.org/10.1016/S0306$\underline{4530(00) 00025-1}$

*Sánchez-Martín, J. R., Azurmendi, A., Pascual-Sagastizabal, E., Cardas, J., Braza, F., Braza, P., ... Muñoz, J. M. (2011). Androgen levels and anger and impulsivity measures as predictors of physical, verbal and indirect aggression in boys and girls. Psychoneuroendocrinology, 36(5), 750-760. https://doi.org/10.1016/j.psyneuen.2010.10.011

*Scaramella, T. J., \& Brown, W. A. (1978). Serum testosterone and aggressiveness in hockey players. Psychosomatic Medicine, 40(3), 262-265. http://doi.org/10.1097/00006842197805000-00007

*Scerbo, A. S., \& Kolko, D. J. (1994). Salivary Testosterone and Cortisol in Disruptive Children: Relationship to Aggressive, Hyperactive, and Internalizing Behaviors. Journal of the American Academy of Child and Adolescent Psychiatry, 40(3), 262-265. https://doi.org/10.1097/00004583-199410000-00013

*Schaal, B., Tremblay, R. E., Soussignan, R., \& Susman, E. J. (1996). Male testosterone linked to high social dominance but low physical aggression in early adolescence. Journal of the American Academy of Child and Adolescent Psychiatry, 35(10), 1322-1330. https://doi.org/10.1097/00004583-199610000-00019

Schwarzer, G., Carpenter, J.R., \& Rücker, G. (2019). metasens: Advanced statistical methods to model and adjust for bias in meta-analysis. $\mathrm{R}$ package version $0.4-0$. https://CRAN.Rproject.org/package $=$ metasens 
*Sjöberg, R. L., Ducci, F., Barr, C. S., Newman, T. K., Dell’Osso, L., Virkkunen, M., \& Goldman, D. (2008). A non-additive interaction of a functional MAO-A VNTR and testosterone predicts antisocial behavior. Neuropsychopharmacology, 33(2), 425-430. https://doi.org/10.1038/sj.npp.1301417

*Soler, H., Vinayak, P., \& Quadagno, D. (2000). Biosocial aspects of domestic violence. Psychoneuroendocrinology, 25(7), 721-739. https://doi.org/10.1016/S0306-4530(00)000226

Spengler, F.B., Schulz, J., Scheele, D., Essel, M., Maier, W., Heinrich, M., \& Hurlemann, R. (2017). Kinetics and dose dependency of intranasal oxytocin effects on amygdala reactivity. Biological Psychiatry, 82(12), 885-894. http://doi:10.1016/j.biopsych.2017.04.015.

Strang, E., Peterson, Z. D., Hill, Y. N., \& Heiman, J. R. (2013). Discrepant responding across selfreport measures of men's coercive and aggressive sexual strategies. Journal of Sex Research, 50(5), 458-469. http://doi.org/10.1080/00224499.2011.646393

*Sunderani, S., Arnocky, S., \& Vaillancourt, T. (2013). Individual differences in mate poaching: An examination of hormonal, dispositional, and behavioral mate-value traits. Archives of Sexual Behavior, 42(4), 533-542. https://doi.org/10.1007/s10508-012-9974-y

*Susman, E. J., Inoff-Germain, G., Nottelmann, E. D., Loriaux, D. L., Cutler, G. B., \& Chrousos, G. P. (1987). Hormones, emotional dispositions, and aggressive attributes in young adolescents. Child Development, 1114-1134. https://doi.org/10.1111/j.14678624.1987.tb01445.x

*Saxbe, D. E., Schetter, C. D., Simon, C. D., Adam, E. K., \& Shalowitz, M. U. (2017). High paternal testosterone may protect against postpartum depressive symptoms in fathers, but confer risk to mothers and children. Hormones and Behavior, https://doi.org/10.1016/j.yhbeh.2017.07.014 
Slatcher, R. B., Mehta, P. H., \& Josephs, R. A. (2011). Testosterone and self-reported dominance interact to influence human mating behavior. Social Psychological and Personality Science, 2(5), 531-539.. https://doi.org/10.1177/1948550611400099

^Tackett, J. L., Reardon, K. W., Herzhoff, K., Page-Gould, E., Harden, K. P., \& Josephs, R. A. (2015). Estradiol and cortisol interactions in youth externalizing psychopathology. Psychoneuroendocrinology, 55, 146-153. https://doi.org/10.1016/j.psyneuen.2015.02.014

Takeshita, R. S. C., Huffman, M. A., Kinoshita, K., \& Bercovitch, F. B. (2017). Effect of castration on social behavior and hormones in male Japanese macaques ( Macaca fuscata ). Physiology \& Behavior, 181, 43-50. http://doi.org/10.1016/j.physbeh.2017.09.006

Trainor, B. C., Bird, I. M., \& Marler, C. A. (2004). Opposing hormonal mechanisms of aggression revealed through short-lived testosterone manipulations and multiple winning experiences. Hormones and Behavior, 45(2), 115-121. https://doi.org/10.1016/j.yhbeh.2003.09.006

*Tremblay, R. E., Schaal, B., Boulerice, B., Arseneault, L., Soussignan, R. G., Paquette, D., \& Laurent, D. (1998). Testosterone, Physical Aggression, Dominance, and Physical Development in Early Adolescence. International Journal of Behavioral Development, 22(4), 753-777. https://doi.org/10.1080/016502598384153

van Rooij, K., de Leede, L., Frijlink, H.W., Bloemers, J., Poels, S., Koppeschaar, H., Olivier, B., \& Tuiten, A. (2014). Pharmacokinetics of a prototype formulation of sublingual testosterone and a buspirone tablet, versus an advanced combination tablet of testosterone and buspirone in healthy premenopausal women. Drug RD, 14(2), 125-132.https://doi: 10.1007/s40268014-0047-7

Vermeersch, H., T’Sjoen, G., Kaufman, J. M., Vincke, J., \& Van Houtte, M. (2010). Testosterone, androgen receptor gene CAG repeat length, mood and behaviour in adolescent males. European Journal of Endocrinology, 163(2), 319-328. https://doi.org/10.1530/EJE-10-0090 
*Victoroff, J., Quota, S., Adelman, J. R., Celinska, B., Stern, N., Wilcox, R., \& Sapolsky, R. M. (2011). Support for religio-political aggression among teenaged boys in Gaza: Part II: Neuroendocrinological findings. Aggressive Behavior, 163(2), 319-328. https://doi.org/10.1002/ab.20376

Viechtbauer, W. (2010). Conducting Meta-Analyses in R with the Metafor package. Journal of Statistical Software, 36(3). http://doi.org/10.18637/jss.v036.i03

*von der, P. B., Sarkola, T., Seppa, K., \& Eriksson, C. J. P. (2002). Testosterone, 5 alphadihydrotestosterone and cortisol in men with and without alcohol-related aggression. Journal of Studies on Alcohol, 63(5), 518-526.

*Vongas, J. G., \& Al Hajj, R. (2017). The effects of competition and implicit power motive on men's testosterone, emotion recognition, and aggression. Hormones and Behavior, 92, 57-71. https://doi.org/10.1016/j.yhbeh.2017.04.005

*Wagels, L., Votinov, M., Kellermann, T., Eisert, A., Beyer, C., \& Habel, U. (2018). Exogenous Testosterone Enhances the Reactivity to Social Provocation in Males. Frontiers in Behavioral Neuroscience, 12, 37. https://doi.org/10.3389/fnbeh.2018.00037

*Walther, A., Waldvogel, P., Noser, E., Ruppen, J., \& Ehlert, U. (2017). Emotions and steroid secretion in aging men: A multi-study report. Frontiers in Psychology, 8, 1722. https://doi.org/10.3389/fpsyg.2017.01722

*Welker, K. M., Norman, R. E., Goetz, S., Moreau, B. J. P., Kitayama, S., \& Carré, J. M. (2017). Preliminary evidence that testosterone's association with aggression depends on self-construal. Hormones and Behavior, 92, 117-127. http://doi.org/10.1016/j.yhbeh.2016.10.014

Wilson, D. B. (2001). Effect size determination program. College Park, MD: University of Maryland.

Wilson, M., \& Daly, M. (1985). Competitiveness, risk taking, and violence: the young male syndrome. Ethology and Sociobiology, 6(1), 59-73. http://doi.org/10.1016/01623095(85)90041-X 
Wingfield, J. C., Hegner, R. E., Dufty, A. M., \& Ball, G. F. (1990). The "Challenge Hypothesis": Theoretical implications for patterns of testosterone secretion, mating systems, and breeding strategies. The American Naturalist, 136(6), 829-846.

*Wolff, S. E., \& Puts, D. A. (2010). Vocal masculinity is a robust dominance signal in men. Behavioral Ecology and Sociobiology, 64(10), 1673-1683. https://doi.org/10.1007/s00265010-0981-5

World Health Organization. (2010). Injuries and violence: the facts. Geneva, Switzerland.

*Yates, W. R., Perry, P. J., MacIndoe, J., Holman, T., \& Ellingrod, V. (1999). Psychosexual effects of three doses of testosterone cycling in normal men. Biological Psychiatry, 45(3), 254-260. http://doi.org/10.1016/S0006-3223(98)00028-6

*Zak, P. J., Kurzban, R., Ahmadi, S., Swerdloff, R. S., Park, J., Efremidze, L., ... Matzner, W. (2009). Testosterone administration decreases generosity in the ultimatum game. PLoS ONE, 4(12), e8330. https://doi.org/10.1371/journal.pone.0008330

*Zethraeus, N., Kocoska-Maras, L., Ellingsen, T., von Schoultz, B., Hirschberg, A. L., \& Johannesson, M. (2009). A randomized trial of the effect of estrogen and testosterone on economic behavior. Proceedings of the National Academy of Sciences, 106(16), 6535-6538. https://doi.org/10.1073/pnas.0812757106

* studies included in the meta-analysis 
Tables

Table 1. Results of the meta-analysis and the moderator analyses (both when moderators were examined individually, and simultaneously in meta-regression) on the relationship between baseline testosterone and aggression.

\begin{tabular}{|c|c|c|c|c|c|c|c|}
\hline Model/Predictor & Estimate $^{a}$ & CI lower & CI upper & $z$ & $p$ & $k$ & $n$ \\
\hline Sex of Sample & 0.071 & 0.011 & 0.131 & 2.322 & .020 & 116 & 15198 \\
\hline Females & 0.002 & -0.041 & 0.044 & 0.081 & .936 & 29 & 2212 \\
\hline Offender Status of Sample & 0.141 & 0.080 & 0.200 & 4.539 & $<.001$ & 116 & 15198 \\
\hline samples involving (exclusively or, in part) offenders & 0.173 & 0.126 & 0.219 & 7.161 & $<.001$ & 18 & 1733 \\
\hline samples not involving offenders & 0.032 & 0.006 & 0.057 & 2.444 & .015 & 98 & 13465 \\
\hline measures collected (exclusively or, in part) outside of the lab & 0.116 & 0.046 & 0.185 & 3.242 & .001 & 22 & 1958 \\
\hline Time of Hormone Determination & -0.049 & -0.099 & 0.002 & -1.879 & .060 & 112 & 15010 \\
\hline samples collected in the morning & 0.077 & 0.039 & 0.114 & 4.003 & $<.001$ & 56 & 10534 \\
\hline samples collected (exclusively or, in part) in the afternoon & 0.026 & -0.005 & 0.057 & 1.628 & .104 & 56 & 4476 \\
\hline Analysis Type (between-subject/group comparison > within/correlational) ${ }^{\mathrm{b}}$ & 0.134 & 0.041 & 0.226 & 2.802 & .005 & 116 & 15198 \\
\hline Publication Year & -0.004 & -0.006 & -0.001 & -3.251 & .001 & 116 & 15198 \\
\hline \multicolumn{8}{|l|}{$\begin{array}{l}\text { Relative contribution of moderators when entered as simultaneous predictors in } \\
\text { a meta-regression }\end{array}$} \\
\hline Intercept & 0.057 & 0.033 & 0.080 & 4.618 & $<.001$ & 112 & 15010 \\
\hline Publication Year & -0.002 & -0.004 & 0.001 & -1.346 & 0.178 & 112 & 15010 \\
\hline Offender Status of Sample (involving > not involving offenders) & 0.110 & 0.036 & 0.184 & 2.899 & 0.004 & 112 & 15010 \\
\hline Time of Hormone Determination (involving < not involving afternoon) & -0.011 & -0.063 & 0.041 & -0.424 & 0.671 & 112 & 15010 \\
\hline Context of Study (outside > within laboratory) & 0.023 & -0.049 & 0.094 & 0.618 & 0.537 & 112 & 15010 \\
\hline
\end{tabular}

Notes. ${ }^{\mathrm{a}}$ Moderators were coded such that estimates indicate the difference in the strength of the association between testosterone and aggression with 1 year change (for Publication Year and Mean Age of the Sample) or between the two moderator levels, within the context of the statistical 
model. ${ }^{b}$ Note that this effect was driven by two effect sizes (when these effects were removed, $p=.147$; see Results section). ${ }^{\mathrm{c}}$ Note that moderators were centred for meta-regression and thus the intercept represents the effect size when each of the moderators are at their mean or-in the case of dichotomous moderators - the average of the two subgroups. 
Table 2. Results of the meta-analysis and the moderator analyses on the relationship between change in testosterone and aggression.

\begin{tabular}{|c|c|c|c|c|c|c|c|}
\hline Model/Predictor & Estimate $^{a}$ & CI lower & CI upper & $z$ & $p$ & $k$ & $n$ \\
\hline Overall Association & 0.108 & 0.041 & 0.174 & 3.168 & 0.002 & 31 & 1463 \\
\hline Sex of the Sample & 0.154 & 0.012 & 0.290 & 2.128 & 0.033 & 31 & 1463 \\
\hline Females & 0.010 & -0.090 & 0.109 & 0.188 & 0.851 & 10 & 469 \\
\hline Country of study & 0.141 & -0.030 & 0.304 & 1.619 & 0.106 & 31 & 1463 \\
\hline Publication Year ${ }^{\mathrm{c}}$ & -0.025 & -0.049 & -0.001 & -2.058 & 0.040 & 31 & 1463 \\
\hline Mean Age of the Sample & 0.010 & -0.030 & 0.050 & 0.489 & 0.625 & 31 & 1463 \\
\hline
\end{tabular}

Notes. There was not enough variability across studies to examine Testosterone Determination Method, Context of Study, Offender Status.

${ }^{a}$ Moderators were coded such that estimates indicate the difference in the strength of the association between testosterone and aggression with 1 year change (for Publication Year and Mean Age of the Sample) or between the two moderator levels, within the context of the statistical model. ${ }^{\mathrm{b}}$ This distribution of effect sizes was not symmetrical (Egger's regression test: $z=2.791, p=0.005$ ); trim and fill analysis and Copas Selection Model Analysis produced smaller estimates (see Results section). ${ }^{\mathrm{c}}$ This marginal effect of Publication Year appeared to be driven by one effect size

(Klinesmith et al., 2006); after its removed, Publication Year became much weaker and was no longer a significant moderator $(z=-0.894, p=.372$ ). ${ }^{\mathrm{d}}$ Although the estimate for this moderator suggests a much larger association in studies using exclusively morning sampling of testosterone, there was only one such study involving exclusively morning sampling (Carré et al., 2014) included in this meta-analysis of change in testosterone, explaining the wide confidence intervals for this estimate. 
Table 3. Results of the meta-analysis and the moderator analyses on the effects of testosterone administration on aggression.

\begin{tabular}{|c|c|c|c|c|c|c|c|}
\hline Model/Predictor & Estimate $^{a}$ & CI lower & CI upper & $z$ & $p$ & $k$ & $n$ \\
\hline Overall Effect & 0.046 & -0.015 & 0.108 & 1.476 & 0.140 & 13 & 1051 \\
\hline Sex of the Sample & 0.045 & -0.114 & 0.203 & 0.556 & 0.578 & 13 & 1051 \\
\hline Females & 0.012 & -0.140 & 0.163 & 0.151 & 0.880 & 2 & 189 \\
\hline Country of study & 0.076 & -0.047 & 0.197 & 1.210 & 0.226 & 13 & 1051 \\
\hline Publication Year & -0.001 & -0.011 & 0.009 & -0.200 & 0.842 & 13 & 1051 \\
\hline Mean Age of the Sample & -0.002 & -0.008 & 0.003 & -0.862 & 0.389 & 13 & 1051 \\
\hline Study design (between < within-subject manipulations) & -0.025 & -0.221 & 0.173 & -0.243 & 0.808 & 13 & 1051 \\
\hline
\end{tabular}

Notes. There was not enough variability across studies or it was not meaningful to examine Testosterone Determination Method, Time of Hormone Determination, Context of Study, Offender Status. ${ }^{a}$ Moderators were coded such that estimates indicate the difference in the strength of the association between testosterone and aggression with 1 year change (for Publication Year and Mean Age of the Sample) or between the two moderator levels, within the context of the statistical model. 


\section{Figure Legends}

Figure 1. Bar graph showing the effect size $(r)$ for the relationship between baseline testosterone and aggression, change in testosterone and aggression, and the effect of exogenous testosterone (vs placebo) on aggression, as a function of sex.

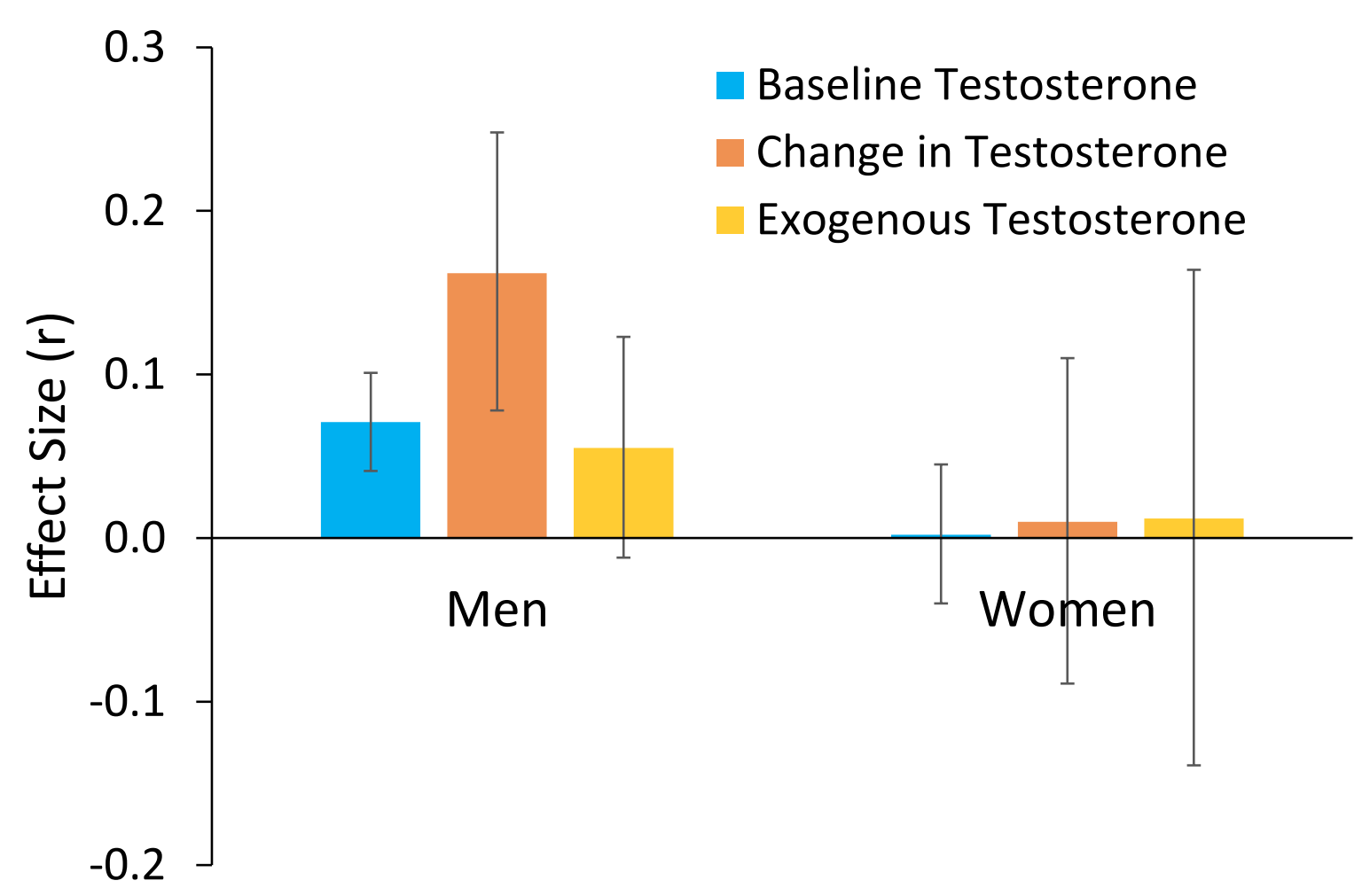


